Article

\title{
Luminescent Ionogels with Excellent Transparency, High Mechanical Strength, and High Conductivity
}

\author{
Lumi Tao ${ }^{1}$, Yuchuan Liu ${ }^{1}$, Dan Wu ${ }^{1}$, Qiao-Hua Wei ${ }^{1}$, Andreas Taubert ${ }^{2, *}$ and Zailai Xie ${ }^{1, *}$ \\ 1 Fujian Provincial Key Laboratory of Electrochemical Energy Storage Materials, College of Chemistry, \\ Fuzhou University, 2 Xueyuan Road, Fuzhou 350002, China; taolumi2020@163.com (L.T.); \\ liuyuchuan86@gmail.com (Y.L.); wdtazjs@163.com (D.W.); qhw76@fzu.edu.cn (Q.-H.W.) \\ 2 Institute of Chemistry, University of Potsdam, 14476 Potsdam, Germany \\ * Correspondence: ataubert@uni-potsdam.de (A.T.); zlxie@fzu.edu.cn (Z.X.); \\ Tel.: +49-0331-977-5773 (A.T.); +86-0-591-22866102 (Z.X.)
}

Received: 3 November 2020; Accepted: 10 December 2020; Published: 15 December 2020

check for updates

\begin{abstract}
The paper describes a new kind of ionogel with both good mechanical strength and high conductivity synthesized by confining the ionic liquid (IL) 1-butyl-3-methylimidazolium bis(trifluoromethane sulfonyl)imide ([Bmim] $\left[\mathrm{NTf}_{2}\right]$ ) within an organic-inorganic hybrid host. The organic-inorganic host network was synthesized by the reaction of methyltrimethoxysilane (MTMS), tetraethoxysilane (TEOS), and methyl methacrylate (MMA) in the presence of a coupling agent, offering the good mechanical strength and rapid shape recovery of the final products. The silane coupling agent 3-methacryloxypropyltrimethoxysilane (KH-570) plays an important role in improving the mechanical strength of the inorganic-organic hybrid, because it covalently connected the organic component MMA and the inorganic component $\mathrm{SiO}_{2}$. Both the thermal stability and mechanical strength of the ionogel significantly increased by the addition of IL. The immobilization of [Bmim] $\left[\mathrm{NTf}_{2}\right]$ within the ionogel provided the final ionogel with an ionic conductivity as high as ca. $0.04 \mathrm{~S} \mathrm{~cm}^{-1}$ at $50^{\circ} \mathrm{C}$. Moreover, the hybrid ionogel can be modified with organosilica-modified carbon dots within the network to yield a transparent and flexible ionogel with strong excitation-dependent emission between 400 and $800 \mathrm{~nm}$. The approach is, therefore, a blueprint for the construction of next-generation multifunctional ionogels.
\end{abstract}

Keywords: ionic liquid; ionogel; carbon dots; organic-inorganic hybrid; luminescence; mechanical strength

\section{Introduction}

Ionic liquids (ILs) have demonstrated great potential for applications in catalysis [1-3], separation [4,5], as electrolyte [6], and in sensors [7]. This is due to their extraordinary properties such as high chemical and thermal stability, high ion conductivity, affinity to inorganic compounds, and wide electrochemical stability windows. One key advantage of ILs is that the IL cations and anions can be adapted to provide an IL with specific properties and hence functionalities [8-11]. Immobilization of free ILs in a solid matrix generates macroscopic solids commonly termed ionogels (IGs). IGs combine the properties of the IL and the host matrix [12,13] and have been put forward for the development of macroscopic solid materials where such a combination of IL properties [14,15] (e.g., ionic conductivity [16] or thermal stability) and properties of a host (e.g., transparency $[17,18]$ or mechanical stability [19]) provides new fields of application. As of now, IGs have been considered for use as solid electrolytes [20,21], solid actuators [22,23], and heterogeneous catalysts [24,25]. These applications often rely on good mechanical strength while maintaining high chemical stability and ionic conductivity. Therefore, new multifunctional IGs combining the above features are highly sought after [26,27]. 
Chemical and structural design of a solid matrix is crucial to tune the physical properties and chemical functions of IGs [14]. To date, numerous solid scaffolds have been used for IG fabrication. Typical examples include inorganic oxides and organic polymers, especially silica and poly(methyl methacrylate) (PMMA) [28-30]. With solvent-casting, a series of soft, magnetic, and luminescent IGs can be fabricated using PMMA as a host [31]. Here, ILs often lead to plasticization that reduces the glass transition temperature of IGs [32]. Moreover, polymer-based IGs often suffer from structural degradation, depolymerization, or leaching when exposed to polar solvents. This severely reduces their use in applications where there is a direct contact with liquid phases.

In contrast, IGs derived from inorganic oxides have better chemical stability [33] and higher ionic conductivity [34] when compared with polymer-based IGs. For example, silica-based IGs can exhibit a tunable phase behavior of ILs [35] and have ionic conductivities as high as $10^{-4} \mathrm{~S} \mathrm{~cm}^{-1}$. However, these IGs are brittle and only have a low mechanical strength. This currently prevents their application in the nascent field of flexible matters [36].

To overcome the issues of both polymer- and inorganic-based IGs, it has recently been proposed that the addition of inorganic nanoparticles to polymer-based IGs may improve the mechanical properties of the material [37-39]. However, the quality of an IG made by this method strongly depends on the properties of inorganic components [40] such as particle size. Moreover, the properties are further affected by processes happening during the IG synthesis, for example phase separation or particle aggregation [31].

As a result, there is a tremendous need for a chemically, electrochemically, and thermally robust IG host material combining the advantages of polymeric and inorganic host materials to afford a true next generation of IGs for application in modern technology. The current article addresses this question. The new IG introduced here exhibits high mechanical strength and high ionic conductivity. Its synthesis is simple and straightforward and is based on confining the IL 1-butyl-3-methylimidazolium bis(trifluoromethane sulfonyl)imide, [Bmim] $\left[\mathrm{NTf}_{2}\right]$ within a new organic-inorganic hybrid host. The organic-inorganic network is obtained by polymerization/condensation of methyltrimethoxysilane (MTMS), tetraethoxysilane (TEOS), and methyl methacrylate (MMA), which provides good mechanical strength and rapid shape recovery characteristics to the final IG. A silane coupling agent $\mathrm{KH}-570$ (3-methacryloxypropyltrimethoxysilane) is used to tightly connect the inorganic and the polymeric components $\left(\mathrm{SiO}_{2}\right.$ and PMMA, respectively) providing the intimate contact between the components and thus excellent mechanical properties to the matrix. IL addition leads to robust but flexible IGs, which can be deformed by an external force and quickly return to the original shape after the external force is removed. The IG exhibits a high ionic conductivity over a range of temperatures and thus is envisioned as a promising solid electrolyte in electronic devices. Finally, luminescent organisilica-containing carbon dots (CDs) can be homogeneously distributed in the IG to yield transparent, flexible, ion conducting, and blue light emitting monolithic materials.

\section{Materials and Methods}

Materials. MMA (99\%), TEOS (99\%), MTMS (99\%), citric acid (99\%+), KH-570 (3-methacryloxypropyltrimethoxysilane, 98\%), and 3-(2-Aminoethylamino) propyl) trimethoxysilane (AEAPTMS, 99\%) were obtained from Adamas Co., Ltd. (Shanghai, China). Azobisisobutyronitrile (AIBN) was procured from Energy Chemical Co., Shangai, China. [Bmim] $\left[\mathrm{NTf}_{2}\right]$ was purchased from Lanzhou Yulu Fine Chemical Co., Ltd., Lanzhou, China. Glucose was supplied by Xilong Scientific Co., Ltd., Shangtou, China. EtOH (analytical purity) was obtained from Sinpharm chemical reagent Co., Ltd., Ningbo, China. All chemicals were used as received.

CD synthesis. Citric acid and AEAPTMS, (mass ratio $=1: 20$ ) were mixed in a Teflon reactor under stirring at room temperature for $0.5 \mathrm{~h}$. The resulting solution was heated to $180{ }^{\circ} \mathrm{C}$ for $12 \mathrm{~h}$ to obtain a yellow uniform liquid. The liquid was extracted with n-hexane to remove unreacted substances. Finally, the residual liquid was removed by rotary evaporation at $60{ }^{\circ} \mathrm{C}$ to obtain a gelatinous yellow powder. 
IG synthesis. A certain amount ( $2 \mathrm{mg}$ ) of CDs were mixed with TEOS ( $2.08 \mathrm{~g}, 0.01 \mathrm{~mol})$ and MTMS $(1.36 \mathrm{~g}, 0.01 \mathrm{~mol})$ in a mixed solvent of ethanol and water (ethanol/water ratio $=1)$ under stirring for $10 \mathrm{~h}$ at room temperature to obtain a uniform liquid. Then, MMA ( $4 \mathrm{~g}, 0.04 \mathrm{~mol})$ and KH-570 (0.62 g, $0.0025 \mathrm{~mol}$ ) were added to the above solution, and the temperature was increased to $65{ }^{\circ} \mathrm{C}$ for $40 \mathrm{~min}$ using an oil bath. After that, $8 \mathrm{mg}$ AIBN and [Bmim][ $\left.\mathrm{NTf}_{2}\right](0.5 \mathrm{~g})$ were added to the solution, and the reaction mixture was kept at $60{ }^{\circ} \mathrm{C}$ for $24 \mathrm{~h}$. Once the gel solidified, the organic-inorganic luminescent IGs were collected.

Characterization. X-ray diffraction was done on a Rigaku Ultima IV (Rigaku, Japan) with a scanning angle range $(2 \theta)$ from $7^{\circ}$ to $85^{\circ}$, with a scan speed of $5^{\circ} / \mathrm{min}$. Attenuated total reflection infrared spectroscopy was done on a ThermoFisher iS50 (Thermo Fisher Scientific, Waltham, MA, USA) from 500 to $4000 \mathrm{~cm}^{-1}$. TGA and differential scanning calorimetry experiments were done on a TA Instruments SDT Q600 TGA (TA Instruments, New Castle, Delaware, USA) from room temperature to $800{ }^{\circ} \mathrm{C}$ in air with a heating rate of $10{ }^{\circ} \mathrm{C} \mathrm{min}-1$. A steady-state transient fluorescence spectrometer (FLS-920, Edinburgh, UK) was used for analyzing the fluorescence absorption and emission phenomena of IGs. Ionic conductivities were measured using a Solartron SI-1260 (Solartron, Zurich, Switzerland) between 25 and $100{ }^{\circ} \mathrm{C}$ and frequencies from 10 to $10^{6} \mathrm{~Hz}$. Field-emission transmission electron microscopy images were obtained on a Talos F200S TEM/STEM (Thermo Fisher Scientific, Waltham, MA, USA) with a S-FEG Schottky gun operated at $200 \mathrm{kV}$. The sample was dispersed with ethanol under sonication for $1 \mathrm{~min}$ and then dipped on a $\mathrm{Cu}$ grid for TEM operation.

\section{Results}

Figure 1 shows that a highly flexible, transparent, and luminescent IG can be fabricated via a two-step process. First, high-brightness blue fluorescent organosilica-modified CDs were synthesized by a simple one-pot hydrothermal method from citric acid and (3-aminopropyl)triethoxysilane (AEAPTMS) as raw materials. The particle sizes of the resulting CDs were roughly distributed between 20 and $30 \mathrm{~nm}$ (see the transmission electron micrograph in Figure 1A).

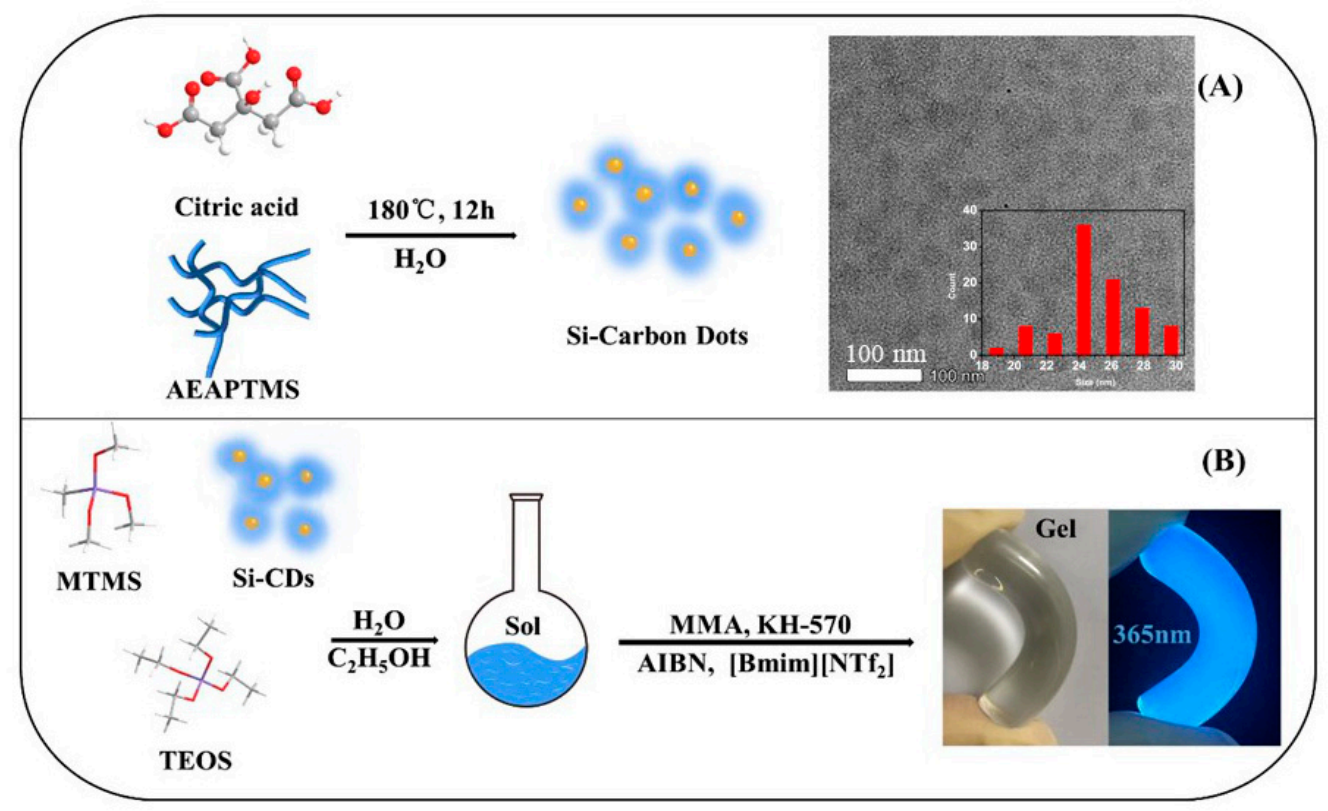

Figure 1. Preparation of carbon dots (CD) (A) and an organic-inorganic hybrid ionogel (IG) (B). AEAPTMS: (3-aminopropyl)triethoxysilane; MTMS: methyltrimethoxysilane; TEOS: tetraethoxysilane; MMA: methylmethacrylate; AIBN: azobisisobutyronitrile; KH-570: 3-methacryloxypropyltrimethoxysilane.

TEOS hydrolyzes to form a $\mathrm{SiO}_{2}$ network, which has a relatively poor mechanical stability due to the brittleness of the $\mathrm{SiO}_{2}$. To obtain a material with good mechanical properties, TEOS and MTMS were 
chosen as inorganic precursors [41], and MMA was selected as an organic component. The bifunctional coupling agent KH-570 was a key component in the material, because it directly bonded the organic component PMMA to the inorganic component $\mathrm{SiO}_{2}$. During the sol-gel process, silane hydrolysis and subsequent silanol condensation formed Si-O-Si bonds (i.e., silica), as by-products water and ethanol formed. At the same time, the free radical copolymerization of MMA and KH-570 was initiated by the thermal decomposition of AIBN, resulting in the formation of PMMA. PMMA provided additional flexibility and stability to the silica network.

Table 1 summarizes the influence of the reactant ratio on the IG properties, such as quantum yield and mechanical properties. Clearly, the quantum yield of the IG increased to 68-69\% after the IL addition. With the addition of organic components, the mechanical properties of the IG also improved. However, the addition of large amounts of the IL led to less favorable mechanical properties.

Table 1. Feed mass ratios, ionic liquids (IL) contents, CD contents, quantum yields (QYs), and plastic strains of the IGs.

\begin{tabular}{cccccccc}
\hline Samples & $\begin{array}{c}\text { TEOS/MTMS/MMA } \\
\text { Feed Mass Ratio }\end{array}$ & IL (g) & CD (mg) & QY (\%) & Tensile strain & $\begin{array}{c}\text { Compressive } \\
\text { Strain }\end{array}$ & $\begin{array}{c}\text { TG Decomposition } \\
\left({ }^{\circ} \text { C) }\right.\end{array}$ \\
\hline A1 & $1: 1: 2$ & 0 & 2 & $36 \%$ & 1.582 & 0.515 & 177.2 \\
A2 & $1: 1: 4$ & 0 & 2 & $32 \%$ & 1.788 & 0.619 & 177.5 \\
A3 & $1: 1: 6$ & 0 & 2 & $30 \%$ & 1.476 & 0.557 & 177.5 \\
A4 & $1: 1: 8$ & 0 & 2 & $29 \%$ & 1.496 & 0.213 & 0.698 \\
A5 & $1: 1: 4$ & 0.5 & 2 & $67 \%$ & 2.884 & 0.840 & 178 \\
A6 & $1: 1: 4$ & 1.0 & 2 & $69 \%$ & 1.474 & 0.747 & 189 \\
A7 & $1: 1: 4$ & 1.5 & 2 & $45 \%$ & 0.715 & 0.544 & 192 \\
A8 & $1: 1: 4$ & 2.0 & 2 & $48 \%$ & 0.340 & & \\
\hline
\end{tabular}

The attenuated total reflection infrared (ATR-IR) spectra of the Si-CD mixture were measured after the dialysis of the CD dispersion against water (Figure 2A). The spectra show bands at 1635 and $3330 \mathrm{~cm}^{-1}$ that can be assigned to the stretching vibration of $\mathrm{C}=\mathrm{O}$ and $-\mathrm{OH}$, respectively. This indicated that the Si-CD mixture contained abundant carbonyl and hydroxyl functional groups. Bands at $1019 \mathrm{~cm}^{-1}$ and $960 \mathrm{~cm}^{-1}$ stemmed from Si-O vibrations, and the $-\mathrm{CH}_{3}$ stretching vibration appeared at $2980 \mathrm{~cm}^{-1}$. The spectra of pure PMMA show a strong band at $1724 \mathrm{~cm}^{-1}$ from the PMMA carbonyl group. The bands at $2951 \mathrm{~cm}^{-1}, 1432 \mathrm{~cm}^{-1}, 1228 \mathrm{~cm}^{-1}, 842 \mathrm{~cm}^{-1}$, and $743 \mathrm{~cm}^{-1}$ originated from aliphatic $\mathrm{C}-\mathrm{H}$ vibrations. The bands at $1271 \mathrm{~cm}^{-1}, 1138 \mathrm{~cm}^{-1}$, and $985 \mathrm{~cm}^{-1}$ were assigned to $\mathrm{C}-\mathrm{O}-\mathrm{C}$ stretching vibrations of PMMA. The bands at $3162 \mathrm{~cm}^{-1}$ and $3123 \mathrm{~cm}^{-1}$ were assigned to the $\mathrm{C}-\mathrm{H}$ vibration of the $[\mathrm{Bmim}]^{+}$cation. The band at $1566 \mathrm{~cm}^{-1}$ stemmed from $\mathrm{C}-\mathrm{C}$ and $\mathrm{C}-\mathrm{N}$ bending vibrations in [Bmim][NTf $\left.{ }_{2}\right]$. The IR spectra of the IG show bands of both PMMA and IL, indicating successful IG formation.

The IR spectrum of [Bmim][NTf $]$ (Figure 2B) shows bands at $3264 \mathrm{~cm}^{-1}, 1572 \mathrm{~cm}^{-1}, 1179 \mathrm{~cm}^{-1}$, and $612 \mathrm{~cm}^{-1}$ that can be assigned to the vibration of $\mathrm{C}-\mathrm{H}$ on the imidazolium ring $[\mathrm{Bmim}]^{+}$. Bands at $2970 \mathrm{~cm}^{-1}, 847 \mathrm{~cm}^{-1}$, and $737 \mathrm{~cm}^{-1}$ were assigned to $-\mathrm{CH}_{2}$ - and $-\mathrm{CH}_{3}$ vibrations on the alkyl side chains. Bands at $1344 \mathrm{~cm}^{-1}$ and $1050 \mathrm{~cm}^{-1}$ stemmed from vibrations of the sulfonyl group in the anion $\left[\mathrm{NTf}_{2}\right]^{-}$. The IR spectra of the IG show the combined characteristic peaks of Si-CD, [Bmim][NTf $\left.{ }_{2}\right]$, the organic component (PMMA), and the inorganic component $\left(\mathrm{SiO}_{2}\right)$, indicative of homogeneous distribution of all constituents.

The TGA data of the organic-inorganic hybrid matrices and the IGs are shown in Figure 3. The first significant weight loss onset temperature of PMMA was below $200{ }^{\circ} \mathrm{C}$. Between room temperature and $300{ }^{\circ} \mathrm{C}$, PMMA lost about $40 \%$ of its mass; the mass loss between $300{ }^{\circ} \mathrm{C}$ and $400{ }^{\circ} \mathrm{C}$ was about $60 \%$. At $400{ }^{\circ} \mathrm{C}$, the PMMA was essentially decomposed, and no residual mass was left. As the curves are broad, detailed assignments were difficult, but the weight losses likely stemmed from overlapping signals from solvent evaporation as well as the evaporation and decomposition of the residual monomer and then, at higher temperatures, resulted from PMMA depolymerization and vaporization along with polymer degradation and carbonization. 

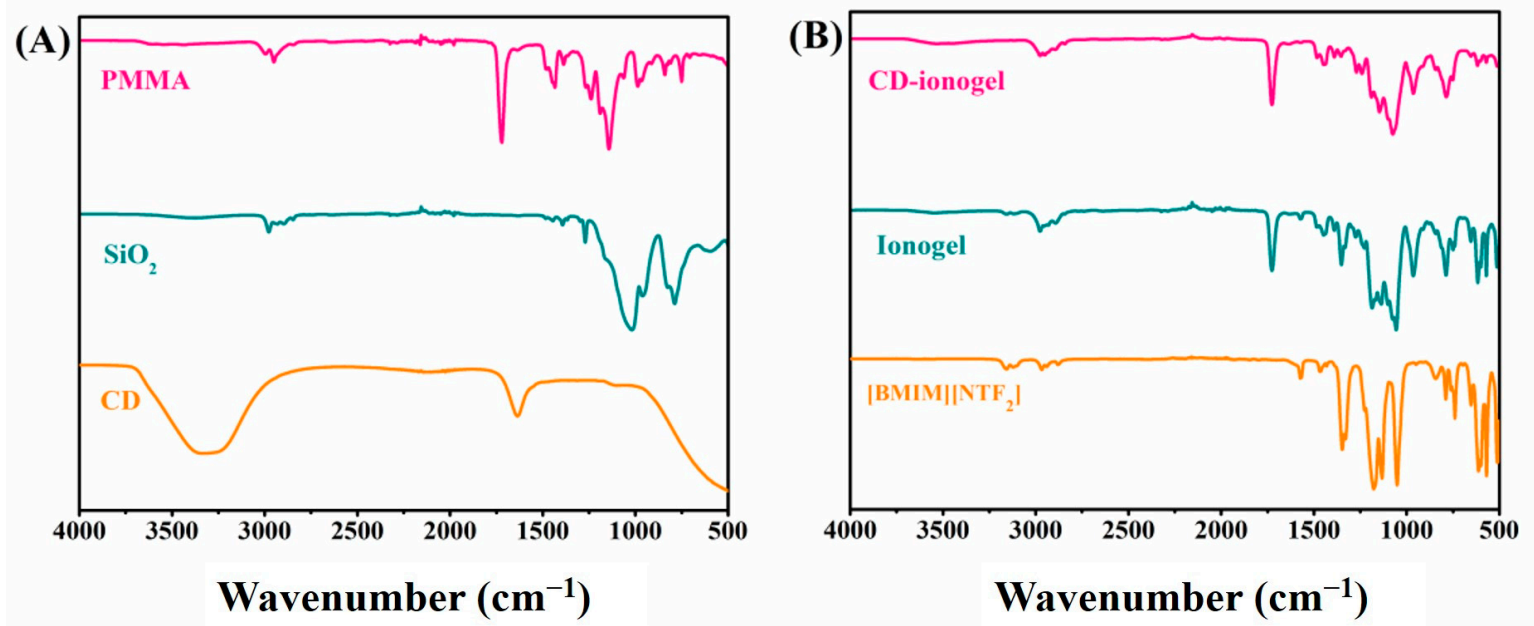

Figure 2. (A) Attenuated total reflection infrared (ATR-IR) spectra of $P M M A, \mathrm{SiO}_{2}$, and CDs. (B) ATR-IR spectra of [Bmim][NTf $\left.{ }_{2}\right]$, the ionogel with a TEOS/MTMS/MMA feed mass ratio of 1:1:4 and $0.5 \mathrm{~g}$ IL, and the CD-ionogel A5.
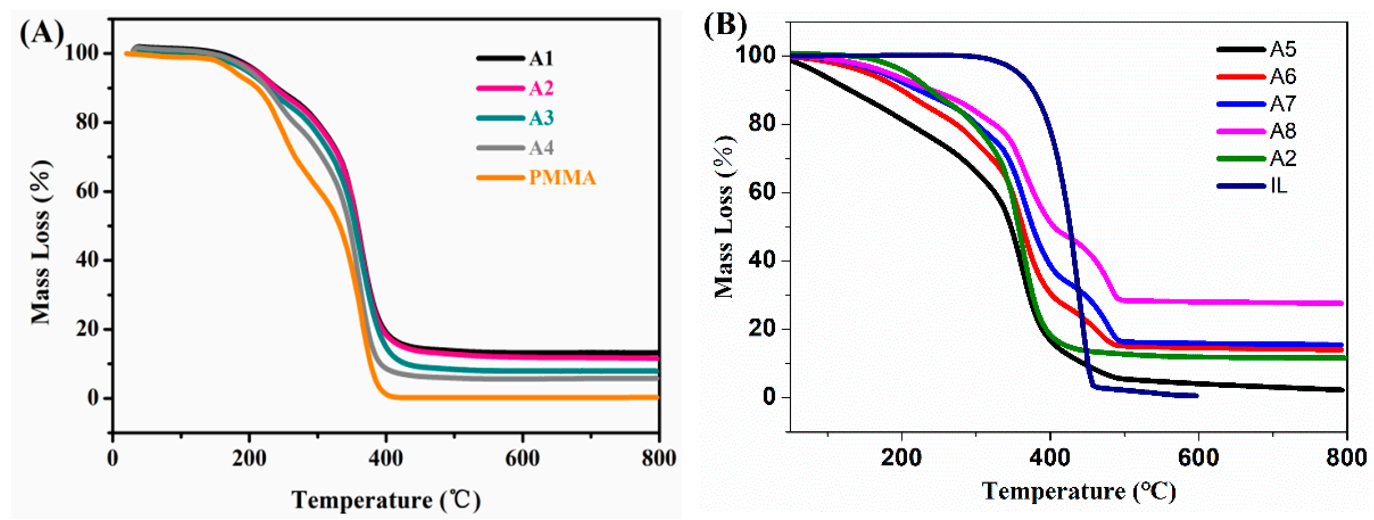

Figure 3. (A) TGA curves of materials A1-A4 with MMA/TEOS/MTMS monomer ratios of 1:1:2, 1:1:4, 1:1:6, and 1:1:8 along with data of PMMA. (B) TGA curves of IGs A5-A8 with 0.5, 1, 1.5, and $2 \mathrm{~g}$ of $[\mathrm{Bmim}]\left[\mathrm{NTf}_{2}\right]$.

Figure $3 \mathrm{~A}$ also shows that as the fraction of the inorganic component increases, the thermal stability of the matrix gradually increased. In contrast to those of PMMA, the weight losses of the four organic-inorganic gels were $68 \%, 71 \%, 76 \%$, and $79 \%$, respectively, with a residue of silica. Likely, the decomposition processes are identical to those just described above. The thermal stability of the IGs was gradually improved upon IL addition. This indicated that the IL acts as a thermal stabilizer, similar to previous reports $[11,28]$ The first weight loss in the TGA data between room temperature and $200{ }^{\circ} \mathrm{C}$ is likely again due to the loss of the organic solvent, the moisture, and the residual monomer. Between $200{ }^{\circ} \mathrm{C}$ and $400{ }^{\circ} \mathrm{C}$, a rather distinct weight loss was visible. Presumably, it stemmed from the decomposition of the organic components, including the IL. Indeed, as the ILs content increased, the thermal stability of the IG increased. The relative intensities of these two weight losses were proportional to the weight fractions of the polymer and IL in the IG, respectively. The TGA, thus, showed that the IL significantly increased the thermal stability of the IG. However, the ratios of the precursor for A2 and A5 were the same, but their thermal stability displayed different behaviors. This can be explained by the fact that the polymerization reaction during the formation of the organic-inorganic hybrid was affected by the ILs. We speculate that the IL could reduce the polymerization degree of the PMMA-SiO 2 matrix, although this would contradict common knowledge of radical polymerization in ILs. 
The ionic conductivities $(\sigma)$ of the matrix and the IGs between $30^{\circ} \mathrm{C}$ and $100^{\circ} \mathrm{C}$ at different IL weight fractions were also investigated. The neat polymer exhibited a very low $\sigma$ of about $3.3 \times 10^{-8} \mathrm{~S} \mathrm{~cm}^{-1}$. After the loading of low IL concentrations, the $\sigma$ values of the IGs were, not surprisingly, much higher than that of the neat polymer. Furthermore, $\sigma$ increased with increasing IL content by several orders of magnitude (the $\sigma$ values of A5-A8 are $1.2 \times 10^{-4}, 5.5 \times 10^{-4}, 1.4 \times 10^{-3}$, and $4.3 \times 10^{-3} \mathrm{~S} \mathrm{~cm}^{-1}$, respectively, at $100{ }^{\circ} \mathrm{C}$ ). Figure $4 \mathrm{~B}$ shows an example of $\sigma$ vs. frequency. The data clearly show that the relationship between $\sigma$ and frequency did not change; this indicated that the IGs were stable and that the materials only showed a very slight dependence of the conductivity in frequency sweeps. The Arrhenius plots of the temperature dependency of $\sigma$ exhibit complex upward/downward curved profiles, which can be fitted with the Vogel-Tamman-Fulcher (VTF) equation for the conductivities of electrolytic materials. The VTF equation was written as:

$$
\sigma=\sigma_{0} \exp \left[-B /\left(T-T_{0}\right)\right]
$$

where the constants, $\sigma_{0}\left(\mathrm{~S} \mathrm{~cm}^{-1}\right), B(\mathrm{~K})$, and $T_{0}(\mathrm{~K})$ are adjustable parameters.
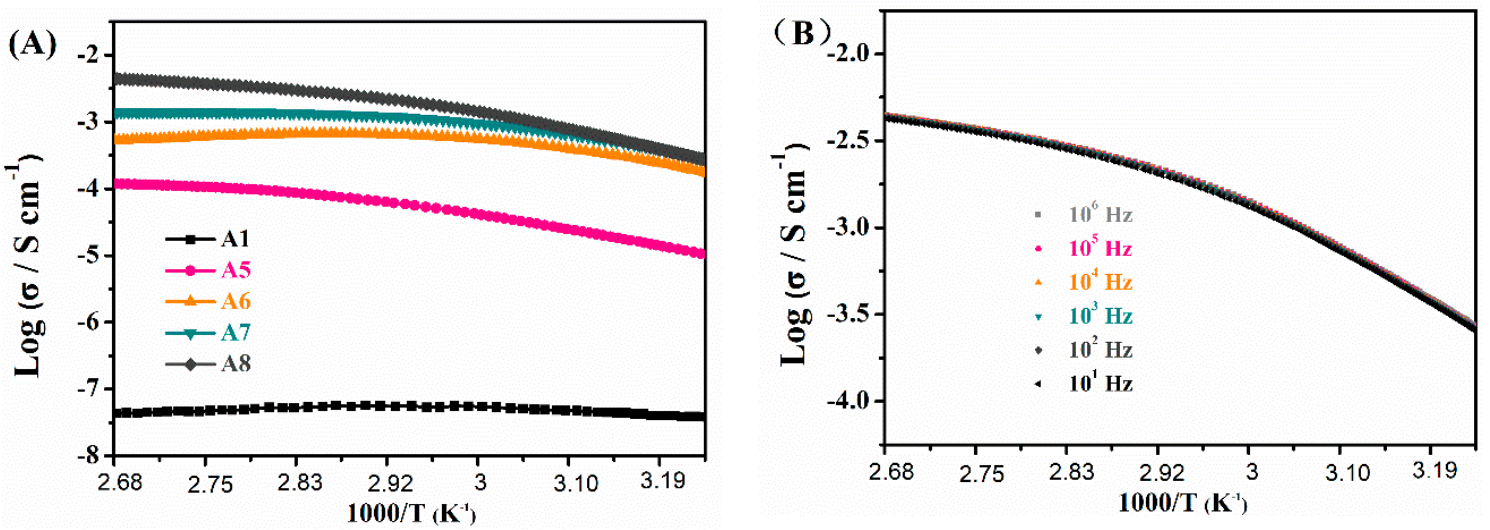

Figure 4. (A) Ionic conductivities of IGs A5 to A8 vs. temperature. The sample A1 (matrix only, no IL) is shown for comparison. (B) Ionic conductivities of A8 at different frequencies and temperatures.

For application of IGs in the nascent field of flexible matter such as a soft robotics, good mechanical properties under strong stress are required. The mechanical analysis of the IGs showed that they can reversibly be compressed without permanent deformation or breakage. This indicated that the IG combined the hardness of the inorganic component with the flexibility of the organic component, and the gel material could quickly recover its shape after removing the applied external force.

Prior to analysis, all samples were fabricated in uniform shape with a cylindrical sample of $1 \mathrm{~cm}$ in diameter and height. Figure 5 shows that all materials exhibited a certain degree of plasticity within an effective elastic deformation range. By exerting and releasing a certain force until $80 \mathrm{~N}$, a hysteresis loop was observed. Figure 5B,C clearly shows that there was a direct dependence of the mechanical properties from the organic and inorganic fractions in the materials. When the inorganic content increased, the material exhibited a higher brittleness and lower elasticity. For example, sample A1 broke at only $20 \mathrm{~N}$, and the compression strain only reached 0.515 while the tensile strain reached 1.582. The IGs with higher organic content showed a higher compression strain of 0.619 (sample A2) and a higher tensile strain of 1.788 (sample A2). This indicated that the idea of an organic-inorganic hybrid is a powerful strategy to improve the mechanical properties of the gels.

In terms of the role the IL plays on the mechanical behavior, the true IGs (A5 to A8) with the ILs fractions of 30-69 wt \% endowed an additional flexibility of the materials. Specifically, Figure 5C,E shows that the compressive plastic strain was increased from 0.619 (A2) to 0.840 (A6) and the tensile plastic strain was increased from 1.788 (A2) to 2.848 (A5). Optically, for the IG with an initial length of $19.5 \mathrm{~mm}$, the maximum deformation displacement reached $56.1 \mathrm{~mm}$. However, with the further 
increase of the IL content, the gel material became relatively soft, leading to low hardness, and exhibited poor mechanical properties and poor plasticity. Overall, by the proper selection of organic components or by IL incorporation, the mechanical properties of IGs can be tuned in a relatively wide range, producing materials that may be suitable in soft electronic device applications.

(A)

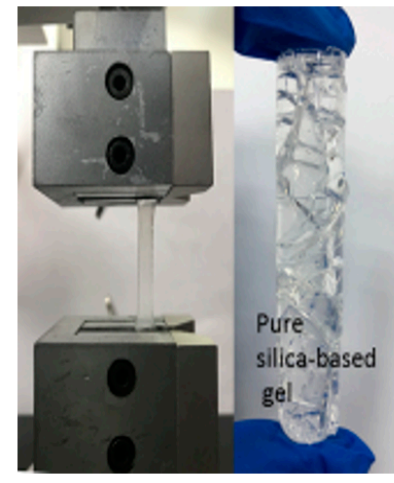

(B)
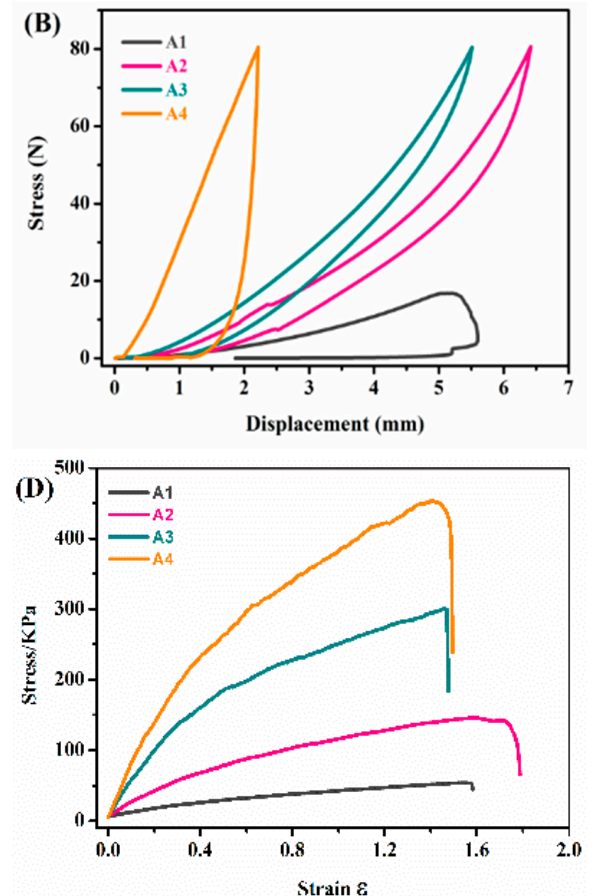
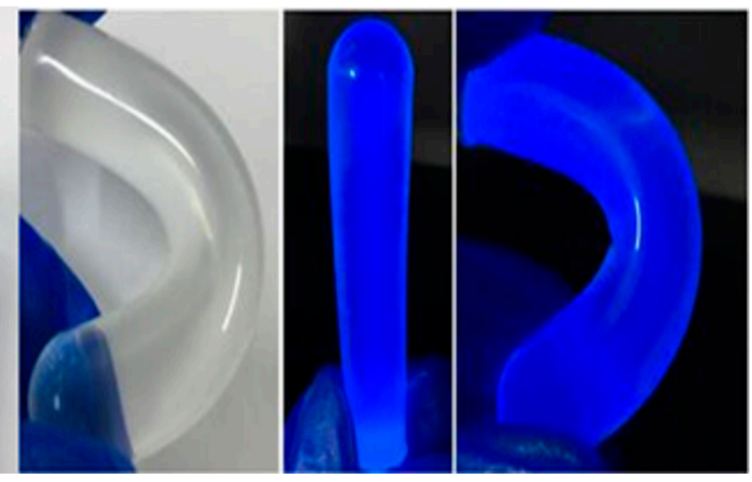

(C)
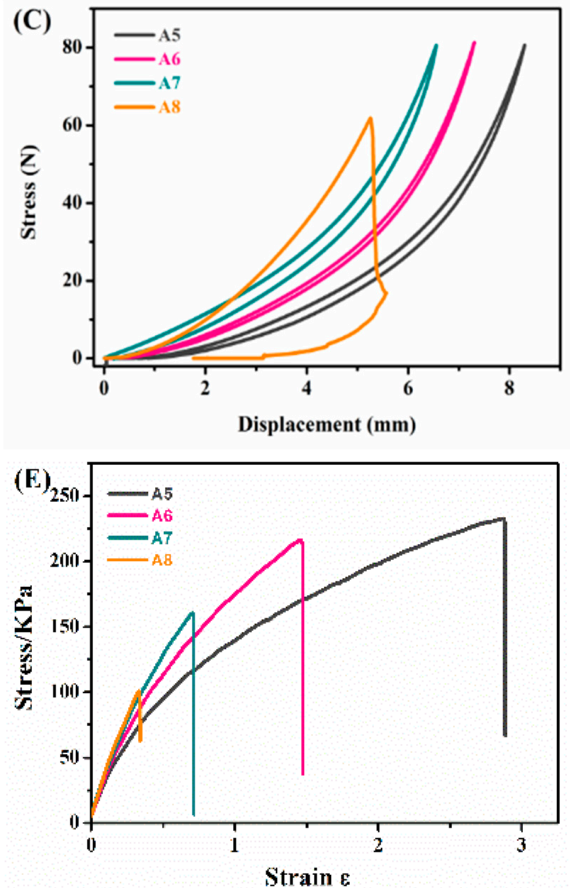

Figure 5. (A) Photographs of an IG in the mechanical analysis setup, a pure silica gel after mechanical treatment, a bent hybrid ionogel, and two images of an ionogel under UV irradiation. (B) Compressive stress-strain curves of A1, A2, A3, and A4. (C) Compressive stress-strain curves of A5, A6, A7, and A8. (D) Tensile stress-strain curves of A1, A2, A3, and A4. (E) Tensile stress-strain curves of A5, A6, A7, and $\mathrm{A} 8$.

Furthermore, to explore the application potential of the IGs, the as-prepared IGs were used as a support to disperse carbon nanoparticles. Here, luminescent CDs were homogeneously dispersed in the IGs-yielding transparent, flexible, ion conducting, and blue light-emitting monolithic materials. Figure 6 (inset) shows that all CDs-doped IGs emitted a bright blue fluorescence under $365 \mathrm{~nm}$ UV irradiation. The further investigation of the absorption and emission behavior showed that the strongest emission was observed upon irradiation at $360 \mathrm{~nm}$ with an emission maximum at ca. $430 \mathrm{~nm}$ and a shoulder at $460 \mathrm{~nm}$, which were mainly attributed to the emissions of CDs. Interestingly, when the IL was added, the fluorescence quantum yields of the gel materials increased significantly from $29 \%$ to $69 \%$. Presumably, the presence of the IL provided a more homogeneous distribution and a more 
stable dispersion of the $\mathrm{CD}$ in the $\mathrm{PMMA}^{-\mathrm{SiO}_{2}}$ polymer. This results in the less aggregation of the CDs favoring an improved intensity of luminescence. The quantum yield (QY) was not linearly related to the IL contents. Rather, the QYs of sample A5 and A6 were 67\% and 69\%, respectively. In general, the addition of IL improved the quantum yield when compared with the IL-free materials, even for A7 (45\%) and A8 (48\%), which contained relatively little IL. This indicated that lower IL contents facilitate the dispersion and stability of CDs and possibly also led to an improved stability of excited states while excessive IL fractions such as in A7 and A8 could result in luminescence quenching.
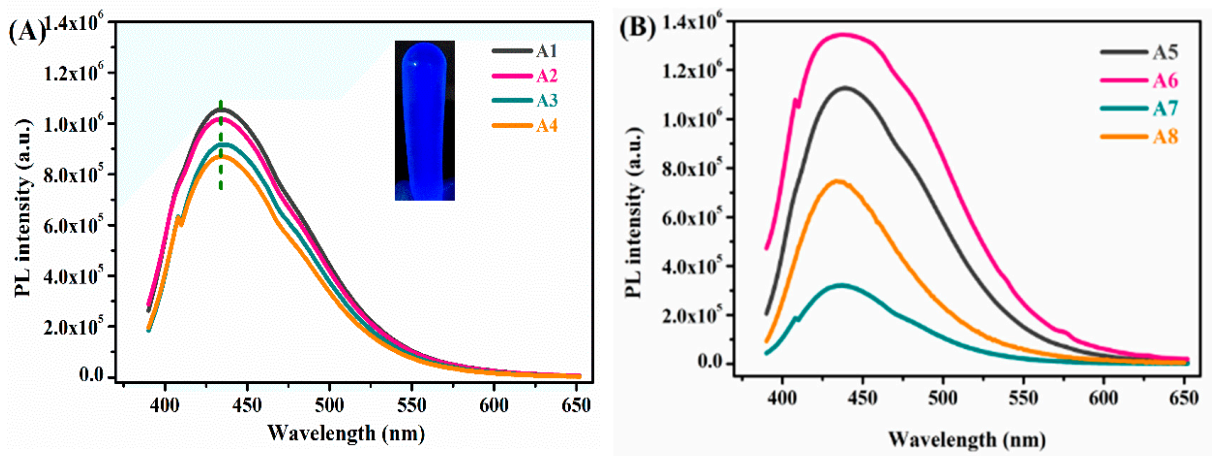

Figure 6. Fluorescence spectra of luminescent gels with different component ratios under $365 \mathrm{~nm}$ UV irradiation. (A) Sample A1-A4; (B) Sample A5-A8.

Excitation-dependent emission is a well-known property of CDs, which could be also observed in the current materials. As shown in Figure 7A, the emission spectra of the CDs in aqueous solutions were observed from $473 \mathrm{~nm}$ (blue emission) to $635 \mathrm{~nm}$ (red emission) upon different wavelength excitations, in which the surface PL emission energy level may come from the distribution of different emission trap sites on the surface of each CD. Different from those in aqueous solutions, the red-shift phenomena could be observed in the IG, accompanied with narrower peaks and increasing intensities. Specifically, the relatively strong emissions in the gels ranged from $439 \mathrm{~nm}$ to $551 \mathrm{~nm}$, which may be attributed to the lower CD concentration in the IG providing less reabsorption of the excitation light by the remaining CDs. However, for high concentrations of CDs, the broad emission peaks may result from the continuous reabsorptions.
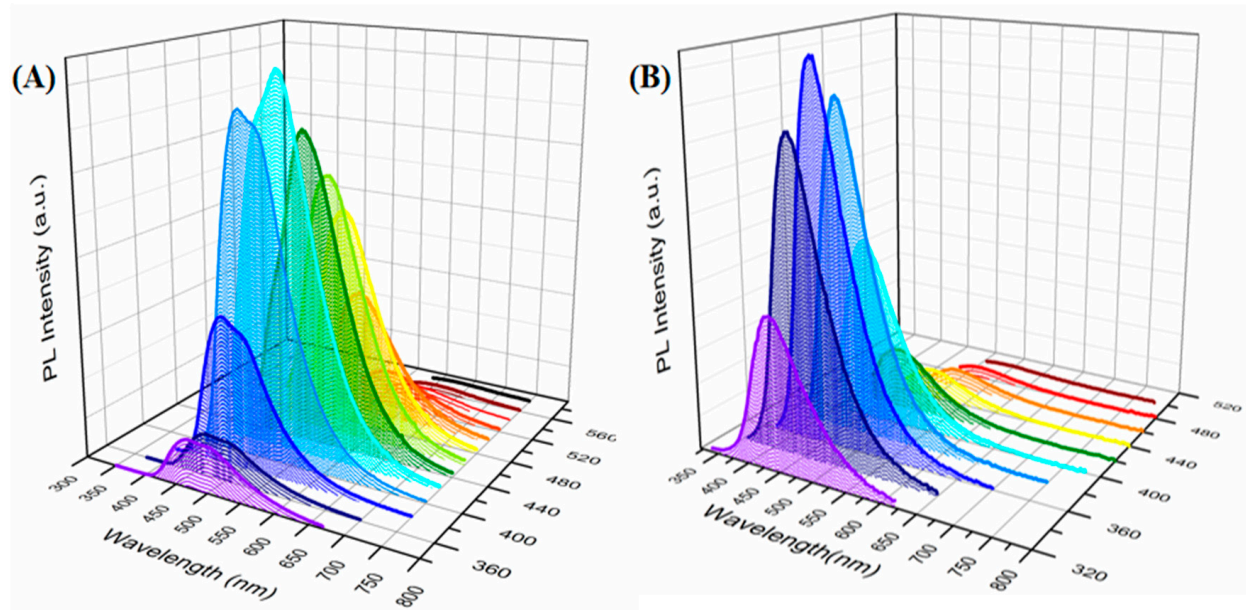

Figure 7. (A) Photoluminescence spectra of the Si-CD aqueous dispersion with excitation wavelengths from $340 \mathrm{~nm}$ to $580 \mathrm{~nm}$ at $20 \mathrm{~nm}$ increments. (B) Photoluminescence spectra of IG A5 with excitation wavelengths from $320 \mathrm{~nm}$ to $500 \mathrm{~nm}$ at $20 \mathrm{~nm}$ increments. 


\section{Conclusions}

A novel organic-inorganic hybrid matrix for advanced IGs has been reported. The major advance over existing IGs is the fact that the combination of sol-gel chemistry with radical polymerization leads to robust, yet flexible, IGs with adjustable mechanical properties, depending on the precursor ratios. Moreover, the resulting materials were multifunctional soft hybrids combining advantageous mechanical properties with interesting optical and electrical properties. Of particular interest, the silane coupling agent 3-methacryloxypropyltrimethoxysilane acted as a bifunctional crosslinker tightly connecting the polymer network with the silica network, providing access to homogeneous materials with tunable properties. Overall, IGs with higher organic content show higher compression strain and tensile strain. The IL [Bmim][ $\left.\mathrm{NTf}_{2}\right]$ immobilized within the flexible gel provided the material with an ionic conductivity as high as ca. $0.04 \mathrm{~S} \mathrm{~cm}^{-1}$ at $50{ }^{\circ} \mathrm{C}$. This indicated that the idea of an organic-inorganic hybrid is a powerful strategy to improve the mechanical and electrical properties of soft matter. Overall, the materials introduced here are prototypes for the development of the next generation of multifunctional IGs with broad application potential.

Author Contributions: L.T., Z.X., and A.T. designed the experiments. L.T., Q.-H.W. and D.W. prepared the samples. Y.L. conducted the TEM characterization and collected the TG data. Z.X. and A.T. supervised the project. L.T. and Z.X. wrote the manuscript. A.T. edited and revised the manuscript and discussed the data. All authors have read and agreed to the published version of the manuscript.

Funding: This work is financially supported by the National Natural Science Foundation of China (22072018), the Natural Science Foundation of Fujian Province (2018J01689), and the University of Potsdam (A.T., 53170000) along with the Publikationsfonds der Universität Potsdam.

Conflicts of Interest: The authors declare no conflict of interest.

\section{References}

1. Zhang, S.; Sun, J.; Zhang, X.; Xin, J.; Miao, Q.; Wang, J. Ionic liquid-based green processes for energy production. Chem. Soc. Rev. 2014, 43, 7838-7869. [CrossRef] [PubMed]

2. Scholten, J.D.; Leal, B.C.; Dupont, J. Transition metal nanoparticle catalysis in ionic liquids. ACS Catal. 2011, 2, 184-200. [CrossRef]

3. Zhang, P.; Wu, T.; Han, B. Preparation of catalytic materials using ionic liquids as the media and functional components. Adv. Mater. 2014, 26, 6810-6827. [CrossRef] [PubMed]

4. Han, X.; Armstrong, D.W. Ionic liquids in separations. Acc. Chem. Res. 2007, 40, 1079-1086. [CrossRef] [PubMed]

5. Pei, Y.; Wang, J.; Wu, K.; Xuan, X.; Lu, X. Ionic liquid-based aqueous two-phase extraction of selected proteins. Sep. Purif. Technol. 2009, 64, 288-295. [CrossRef]

6. Wu, F.; Chen, N.; Chen, R.; Wang, L.; Li, L. Organically modified silica-supported ionogels electrolyte for high temperature lithium-ion batteries. Nano Energy 2017, 31, 9-18. [CrossRef]

7. Zhang, L.M.; He, Y.; Cheng, S.; Sheng, H.; Dai, K.; Zheng, W.J.; Wang, M.X.; Chen, Z.S.; Chen, Y.M.; Suo, Z.; et al. Self-healing, adhesive, and highly stretchable ionogel as a strain sensor for extremely large deformation. Small 2019, 15, 1804651. [CrossRef]

8. Chiappe, C.; Pieraccini, D. Ionic liquids: Solvent properties and organic reactivity. J. Phys. Org. Chem. 2005, 18, 275-297. [CrossRef]

9. Hapiot, P.; Lagrost, C. Electrochemical reactivity in room-temperature ionic liquids. Chem. Rev. 2008, 108, 2238-2264. [CrossRef]

10. Visentin, A.F.; Alimena, S.; Panzer, M.J. Influence of ionic liquid selection on the properties of Poly(ethylene glycol) diacrylate-supported ionogels as solid electrolytes. ChemElectroChem 2014, 1, 718-721. [CrossRef]

11. Xie, Z.L.; Huang, X.; Taubert, A. DyeIonogels: Proton-responsive ionogels based on a dye-ionic liquid exhibiting reversible color change. Adv. Funct. Mater. 2014, 24, 2837-2843. [CrossRef]

12. Marr, P.C.; Marr, A.C. Ionic liquid gel materials: Applications in green and sustainable chemistry. Green Chem. 2016, 18, 105-128. [CrossRef] 
13. Visentin, A.F.; Dong, T.; Poli, J.; Panzer, M.J. Rapid, microwave-assisted thermal polymerization of poly(ethylene glycol) diacrylate-supported ionogels. J. Mater. Chem. A 2014, 2, 7723. [CrossRef]

14. Horowitz, A.I.; Panzer, M.J. Poly(dimethylsiloxane)-supported ionogels with a high ionic liquid loading. Angew. Chem. Ent. Ed. 2014, 53, 9780-9783. [CrossRef]

15. Xie, Z.L.; Xu, H.B.; Geßner, A.; Kumke, M.U.; Priebe, M.; Fromm, K.M.; Taubert, A. A transparent, flexible, ion conductive, and luminescent PMMA ionogel based on a Pt/Eu bimetallic complex and the ionic liquid [Bmim][N(Tf $\left.)_{2}\right]$. J. Mater. Chem. 2012, 22, 8110. [CrossRef]

16. Delahaye, E.; Göbel, R.; Löbbicke, R.; Guillot, R.; Sieber, C.; Taubert, A. Silica ionogels for proton transport. J. Mater. Chem. 2012, 22, 17140. [CrossRef]

17. Neouze, M.A.; Le Bideau, J.; Leroux, F.; Vioux, A. A route to heat resistant solid membranes with performances of liquid electrolytes. Chem. Commun. 2005, 1082-1084. [CrossRef]

18. Néouze, M.A.; Le Bideau, J.; Gaveau, P.; Bellayer, S.; Vioux, A. Ionogels, new materials arising from the confinement of ionic liquids within silica-derived networks. Chem. Mater. 2006, 18, 3931-3936. [CrossRef]

19. Le Bideau, J.; Viau, L.; Vioux, A. Ionogels, ionic liquid based hybrid materials. Chem. Soc. Rev. 2011, 40, 907-925. [CrossRef]

20. Chen, N.; Zhang, H.; Li, L.; Chen, R.; Guo, S. Ionogel electrolytes for high-performance lithium batteries: A review. Adv. Energy Mater. 2018, 8, 1702675. [CrossRef]

21. Visentin, A.F.; Panzer, M.J. Poly(ethylene glycol) diacrylate-supported ionogels with consistent capacitive behavior and tunable elastic response. ACS Appl. Mater. Interfaces 2012, 4, 2836-2839. [CrossRef] [PubMed]

22. Thiemann, S.; Sachnov, S.J.; Pettersson, F.; Bollström, R.; Österbacka, R.; Wasserscheid, P.; Zaumseil, J. Cellulose-based ionogels for paper electronics. Adv. Funct. Mater. 2014, 24, 625-634. [CrossRef]

23. Terasawa, N. High-performance transparent actuator made from poly(dimethylsiloxane)/ionic liquid gel. Sens. Actuat. B Chem. 2018, 257, 815-819. [CrossRef]

24. Debecker, D.P.; Mutin, P.H. Non-hydrolytic sol-gel routes to heterogeneous catalysts. Chem. Soc. Rev. 2012, 41, 3624-3650. [CrossRef]

25. Wang, Y.M.; Ulrich, V.; Donnelly, G.F.; Lorenzini, F.; Marr, A.C.; Marr, P.C. A Recyclable acidic ionic liquid gel catalyst for dehydration: Comparison with an analogous SILP catalyst. ACS Sustain. Chem. Eng. 2015, 3, 792-796. [CrossRef]

26. Lee, J.H.; Lee, A.S.; Lee, J.C.; Hong, S.M.; Hwang, S.S.; Koo, C.M. Hybrid ionogel electrolytes for high temperature lithium batteries. J. Mater. Chem. A 2015, 3, 2226-2233. [CrossRef]

27. Tan, G.; Wu, F.; Zhan, C.; Wang, J.; Mu, D.; Lu, J.; Amine, K. Solid-state li-ion batteries using fast, stable, glassy nanocomposite electrolytes for good safety and long cycle-life. Nano Lett. 2016, 16, 1960-1968. [CrossRef]

28. Yang, F.; Wu, D.; Luo, Z.; Tan, B.; Xie, Z. Hybrid organic-inorganic dyeionogels: Reversibly pH-responsive materials based dye-ionic liquids with improved structural stability and flexibility. Sens. Actuat. B Chem. 2017, 249, 486-492. [CrossRef]

29. Jiang, J.; Gao, D.; Li, Z.; Su, G. Gel polymer electrolytes prepared by in situ polymerization of vinyl monomers in room-temperature ionic liquids. React. Funct. Polym. 2006, 66, 1141-1148. [CrossRef]

30. Gayet, F.; Viau, L.; Leroux, F.; Mabille, F.; Monge, S.; Robin, J.J.; Vioux, A. Unique combination of mechanical strength, thermal stability, and high ion conduction in PMMA-silica nanocomposites containing high loadings of ionic liquid. Chem. Mater. 2009, 21, 5575-5577. [CrossRef]

31. Horowitz, A.I.; Westerman, K.; Panzer, M.J. Formulation influence on the sol-gel formation of silica-supported ionogels. J. Sol Gel Sci. Technol. 2016, 78, 34-39. [CrossRef]

32. Susan, M.A.; Kaneko, T.; Noda, A.; Watanabe, M. Ion gels prepared by in situ radical polymerization of vinyl monomers in an ionic liquid and their characterization as polymer electrolytes. J. Am. Chem. Soc. 2005, 127, 4976-4983. [CrossRef] [PubMed]

33. Guyomard-Lack, A.; Abusleme, J.; Soudan, P.; Lestriez, B.; Guyomard, D.; Bideau, J.L. Hybrid silica-polymer ionogel solid electrolyte with tunable properties. Adv. Energy Mater. 2014, 4, 1301570. [CrossRef]

34. Cheng, Y.; Lu, S.; Zheng, R.; Zhang, D.; Zhang, H. Silica-based ionogel electrolyte with porous flower-like structure enables safer lithium ion battery. Appl. Surf. Sci. 2019, 485, 119-127. [CrossRef]

35. Song, H.; Luo, Z.; Zhao, H.; Luo, S.; Wu, X.; Gao, J.; Wang, Z. High tensile strength and high ionic conductivity bionanocomposite ionogels prepared by gelation of cellulose/ionic liquid solutions with nano-silica. RSC Adv. 2013, 3, 11665-11675. [CrossRef] 
36. Horowitz, A.I.; Panzer, M.J. High-performance, mechanically compliant silica-based ionogels for electrical energy storage applications. J. Mater. Chem. 2012, 22, 16534. [CrossRef]

37. Kato, T.; Okazaki, A.; Hayase, S. Latent gel electrolyte precursors for quasi-solid dye sensitized solar cells. Chem. Commun. 2005, 363-365. [CrossRef]

38. Shimano, S.; Zhou, H.; Honma, I. Preparation of nanohybrid solid-state electrolytes with liquidlike mobilities by solidifying ionic liquids with silica particles. Chem. Mater. 2007, 19, 5216-5221. [CrossRef]

39. Ding, Y.; Zhang, J.; Chang, L.; Zhang, X.; Liu, H.; Jiang, L. Preparation of high-performance ionogels with excellent transparency, good mechanical strength, and high conductivity. Adv. Mater. 2017, 29, 1704253. [CrossRef]

40. Zhang, B.; Xue, Y.; Xue, Z.; Li, Z.; Hao, J. A green synthesis of nanosheet-constructed Pd particles in an ionic liquid and their superior electrocatalytic performance. ChemPhysChem 2015, 16, 3865-3870. [CrossRef]

41. Taubert, A.; Löbbicke, R.; Kirchner, B.; Leroux, F. First examples of organosilica-based ionogels: Synthesis and electrochemical behavior. Beilstein J. Nanotechnol. 2017, 8, 736-751. [CrossRef] [PubMed]

Publisher's Note: MDPI stays neutral with regard to jurisdictional claims in published maps and institutional affiliations.

(C) 2020 by the authors. Licensee MDPI, Basel, Switzerland. This article is an open access article distributed under the terms and conditions of the Creative Commons Attribution (CC BY) license (http://creativecommons.org/licenses/by/4.0/). 